\title{
SCRIITORI ROMÂNI DE EXPRESIE STRĂINĂ TRADUCĂTORI AI OPERELOR ROMÂNEŞTI: CAZUL ANDREI CODRESCU
}

\author{
ROMANIAN FOREIGN LANGUAGE WRITERS - \\ TRANSLATORS OF ROMANIAN LITERARY WORKS: \\ THE CASE OF ANDREI CODRESCU
}

\author{
Luiza MARINESCU1 \\ https://doi.org/10.52744/9786062613242.18
}

\begin{abstract}
Rezumat: În tradiția literaturii şi a alcătuirii istorïlor literare există datina integrării în conținutul acestora a operelor publicate în limba respectivă şi în țara respectivă pentru prima dată. Ca urmare scriitorï de origine dintr-o anumită țară, de expresie străină sunt de cele mai multe ori uitați, pe motiv că sunt revendicați de literaturile din limbile de adopție ale creațiilor lor. In cazul literaturii române, există mai multe generații de scriitori cu exprimare multilingvistică. Dacă în perioada medievală limba de cultură folosită de anumite cancelarii şi curți a fost diferită de limba română, scriitorii respectivi au reuşit să devină cunoscuți mai ales prin intermediul limbii internaționale de cultură a momentului şi a locului. Capitolul de față analizează cazul lui Andrei Codrescu, un scriitor care a transformat experiența exilului într-o carieră universitară profitabilă , in lumina literaturii pure.
\end{abstract}

Cuvinte cheie: Literatura română; Exil; Literatura americană; Literatura ebraică; Literatura contemporană

\begin{abstract}
The literary tradition and the production of literary histories has long focused upon "national literature," which is to say those works written in the tongue of the country in question. As a result, writers of Romanian origin who lived in a foreign country and wrote in the language of their host country were often overlooked by Romanian critics, because such writers were considered to be exponents of the national literatures of the foreign countries in which they resided. In the case of Romanian literature, there are several generations of writers of multilingual expression, and the above dynamic has proven to be the case for a very long time. Throughout the centuries, the language of administration and culture was often different from Romanian vernacular, and the writers who managed to become internationally known were those writing in the language of culture rather than those writing in Romanian. This study analyzes the work of Andrei Codrescu, a Romanian-American writer who managed to transform his experience of exile into a "Road Scholar" (according to his film of this name) leading to a profitable university career enlightened by literature.
\end{abstract}

${ }^{1}$ Conf. univ. dr., Universitatea Spiru Haret University, Bucureşti, luizamarinescu70o @hotmail.com 
Keywords: Romanian Literature; Exile; American Literature; Jewish Literature; Contemporary Literature

În tradiția literaturii şi a alcătuirii istoriilor literare există datina integrării în conținutul acestora a operelor publicate în limba respectivă şi în țara respectivă pentru prima dată. Ca urmare scriitorii de origine dintr-o anumită țară, de expresie străină sunt de cele mai multe ori uitați, pe motiv că sunt revendicați de literaturile din limbile de adopție ale creațiilor lor. În cazul literaturii române, există mai multe generații de scriitori cu exprimare multilingvistică. Dacă în perioada medievală limba de cultură folosită de anumite cancelarii şi curți a fost diferită de limba română, scriitorii respectivi au reuşit să devină cunoscuți mai ales prin intermediul limbii internaționale de cultură a momentului şi a locului. Aşa au fost cunoscuți Dimitrie Cantemir, Miron Costin şi Nicolae Milescu Spătarul. În veacul al XIX-lea şi al XX-lea, educaţia scriitorilor în limbi de circulație i-a făcut pe aceştia să prefere exprimarea literară în limbile pe care le exersaseră prin educație: Vasile Alecsandri, Mircea Eliade, Nicolae Iorga, Alexandru Macedonski, Costache Aristia, George Astaloş, Elena Bacaloglu, Linda Maria Baros, Horia Bădescu, Gheorghe Băgulescu, Mariana Bendou, Martha Bibescu, Alexandru Bogdan-Piteşti, Lucian Boia, Ion C. Brătianu, François Bréda, Denis Buican, George Matei Cantacuzino, Matei Cazacu, Emil Cioran, Alexandru Ciorănescu, Adrian Cioroianu, Claymoor, Nicolae Cocea, Dora d'Istria, Mircea Demetriade, George Diamandy, Neagu Djuvara, Petru Dumitriu, Ştefan Fay, Constantin Virgil Gheorghiu, Vladimir Ghika, Paul Goma, Sergiu Grossu, Spiru Haret, Iulia Hasdeu, Ion Heliade-Rădulescu, Vintilă Horia, Virgil Ierunca, Panait Istrati, Ioan Kalinderu, Horia Liman, Monica Lovinescu, Adrian Marino, Leon M. Negruzzi, Ana, contesă de Noailles, Alexandru Odobescu, Oana Orlea, Alexandru Paleologu, Radu Rosetti, Alecu Russo, Elias Schwarzfeld, George Barbu Ştirbei, Virgil Tănase, Păstorel Teodoreanu, Dimitrie-Doru Todericiu, Nicolas Trifon, Tristan Tzara, Alexandru Tzigara-Samurcaş, Dumitru Țepeneag, V. A. Urechia, Elena Văcărescu, Nicole Valéry-Grossu, Ion Vinea, Matei Vişniec, Ilarie Voronca, Nicolae Xenopol, Alexandru Zub. Literatura română de expresie germană din România a fost reprezentată de la sfârşitul secolului al XIX-lea prin Richard Adleff, Georg Aescht, Michael Albert (scriitor sas), Otto Alscher, Elisabeth Axmann, Ursula Bedners, Anton Breitenhofer, Iosif C. Mătăsaru, Otto Czekelius, Ignaz Bernhard Fischer, Walter Hatzack, Nikolaus Hans Hockl, Franz Hodjak, Richard Jakobi, Samuel Kastriener, Michael Kroner, Ernst Kulcsar, Anna Elisabeth Kunesch, Anemone Latzina, Heinrich Lauer, Hans Liebhardt, Andreas A. Lillin, Alfred Margul-Sperber, Adolf Meschendörfer, Oskar Paulini, Annemarie 
Podlipny-Hehn, Erika Scharf, Georg Scherg, Hellmut Seiler, August von Spiess, Heinz Stănescu, Johann Steiner, Claus Stephani, Anton Sterbling, Franz Storch, Ricarda Terschak, Traugott Teutsch, Anneliese Thudt, Alexander Tietz, William Totok, Anton Valentin, Richard Wagner (scriitor), Balthasar Waitz, Georg Weiner, Immanuel Weissglas, Horst Wichland, Ernest Wichner, Emil Witting, Erwin Wittstock, Joachim Wittstock, Oskar Wittstock, Hans Wühr, Willi Zeidner, Katharina ZerbesMărgineanu, Heinrich Zillich, Silvia Irina Zimmermann, Josef Zirenner, Alwin Zweyer, Carmen Sylva, Gustav Seivert şi Josef Marlin, iar în secolul al XX-lea prin Bucura Dumbravă, Erwin Wittstock, Adolf Meschendörfer, Heinrich Zillich şi Oscar Walter Cisek, redactorii secțiunii de limba germană ai revistei clujene Echinox Peter Motzan (1968-1972), Werner Sôllner (1972-1975), Georg Aescht (1975-1976), Edith Konradt (19761977), Helmut Britz si Anton Seitz (1977- 1980), Klaus Schneider si Maria Schullerus (1981-1982), Ute Roth (1983), precum şi scriitorii care s-au impus în statele de limbă germană imediat după emigrare: Oskar Pastior, Franz Hodjak sau Werner Sollner, Richard Wagner, Hertha Muller, Klaus Hensel, Georg Aescht, Rolf Bossert, Gerhard Csejka, Berndt Kolf, Ernest Wichner, William Totok, Helmut Britz, Klaus Schneider, Johann Lippet, Christian W. Schenk sau Ingmar Brantsch. Scriitorii saşi născuţi în Transilvania întregesc contextul cultural multilingvistic european prin nume precum: Peter Barth, Andreas Birkner, Werner Bossert, Alexander Czoppelt, Fred Fakler, Johann Filstich, Walter Hatzack, Georg Hoprich, Hermann Klöß, Sepp Komanschek, Michael Königes, Ernst Kühlbrandt, Ernst Kulcsar, Hans Liebhardt, Misch Maier, Joseph Marlin, Hilde Martini-Striegl, Adolf Meschendörfer, Otto Piringer, Paul Rampelt, Karl Gustav Reich, Georg Reypchius, Georg Scherg, Heinrich Simonis, Traugott Teutsch, Oskar Wittstock, Willi Zeidner, Alwin Zweyer. Literatura germană din Bucovina reprezentată de Berthold Frucht, Franz Porubsky sau Fritz Poppenberger face şi ea parte din circuitul de schimburi culturale ale diverselor regiuni şi enclave de limbă germană ale fostului Imperiu Austro-Ungar. Cazul scriitorului Andrei Codrescu este studiat din perspectiva afirmării sale pe un culoar lingvistic care i-a permis accesul la notorietate şi care l-a determinat să revină pe matricea lingvistică în care a fost educat pentru a promova prin traduceri literatura țării sale de baştină.

Scriitorul american de origine română Andrei Codrescu este un creator de notorietate în literatura contemporană, fiind autor de roman, poezie, eseistică, proză biografică şi proza jurnalistică americană în formele ei radiofonice, de televiziune sau tipărite. Considerat scriitor român (Vanoaga, 2019; Gheo, 2017; Strugaru, 2013.) deopotrivă, precum şi scriitor evreu (Rosenfeld, 2008.), el s-a născut la Sibiu, purtând numele 
de Andrei Perlmutter. A debutat cu poezie sub numele de Andrei Steiu, fiind prezent la cenaclurile literare de la Cluj şi de la Sibiu. În cele din urmă, numele care l-a consacrat a fost Andrei Codrescu. La vârsta de 20 de ani, a avut şansa de a emigra, guvernul de atunci primind 6000 de dolari din partea israeliană pentru reprezentanții etniei, care îşi doreau să plece din țară în Israel. După ce a emigrat şase luni în Italia, la Napoli şi la Roma, a ajuns la Detroit în cea mai tulbure perioadă din istorie, stabilindu-se la New Orleans, în Statele Unite, a continuat să scrie în limba engleză poezie, intrând în cercul poeților şi al teoreticienilor The New York School, unde fără îndoială că a descoperit consonanțe armonice. S-a împrietenit întâmplător cu Allen Ginsberg, poetul reprezentativ al aşa-numitei Beat Generation la Roma şi această prietenie l-a impulsionat şi l-a adus în apropierea unor modele puternice de atracție spre frumusețea şi grația poeziei. Geniul şi puterea creativităţii sale au început să dezvăluie frumusețea universului învăluit prin poezie. Profesor la mai multe universități americane, Andrei Codrescu este editorul publicației Exquisite Corpse: A Journal of Books \& Ideas. ${ }^{2}$, a creat mai multe decenii la National Public Radio emisiunea All Things Considered. A coordonat mai multe antologii de poeziei americană American Poets Say Goodbye to the 2oth Century (1996) şi American Poetry Since 1970: Up Late (1996). A colaborat cu Ruxandra Cesereanu la The Forgiven Submarine (2009).

Andrei Codrescu este cunoscut şi pentru extraordinarul dar al povestirii fiind un maestru al recreării atmosferei: Whatever Gets You through the Night: A Story of Sheherezade and the Arabian Entertainments (2011); The Poetry Lesson (2010), un jurnal de curs; The Posthuman Dada Guide: Tzara \& Lenin Play Chess (2009); volumul de memorialistică The Hole in the Flag: A Romanian Exile's Story of Return and Revolution (1991). Este autorul unui film prezentat şi premiat cu Peabody Award ca cel mai bun documentar la Seattle International Film Festival şi la the San Francisco International Film Festival în 1993: Road Scholar, A predate la Johns Hopkins University, the University of Baltimore şi la Louisiana State University, unde a primit distincția the MacCurdy Distinguished Professor of English până la pensionarea sa din 2009.

Inclus în mai multe istorii ale literaturii americane contemporane, pentru extraordinar de bogata activitate literară care cuprinde aproape toate genurile de scriere, Andrei Codrescu este cel care îl face cunoscut în universul limbii engleze prin intermediul traducerii pe Lucian Blaga, unul dintre cei mai importanți poeți, dramatugi, traducători, romancieri, diplomați şi filosofi ai secolului al XX-lea, o voce binecunoscută în cultura română în perioada 1919-1949. Activitatea sa a fost trecută pe o linie

${ }^{2}$ http://www.corpse.org/archives/gang/index.html consultat la data de 28 august 2020 
absurdă odată cu instaurarea regimului sovietic care s-a răzbunat cumplit pe generația de intelectuali care contribuiseră la realizarea României Mari: demis din Universitate, cu greu angajat ca bibliotecar, propus pentru premiul Nobel în 1956, nominalizarea sa este refuzată de guvernul sovieto-comunist, care îşi trimisese doi emisari să protesteze în Suedia pentru nominalizare, cu toate cărțile puse la index până în 1962.

Andrei Codrescu a avut şansa să îi cunoască poeziile în anii adolescenței când un inimos profesor de literatură de la Sibiu i-a dat cărțile să le citească, iar acesta le-a adus cu sine în America, unde poezia lui Blaga a început să se topească în engleză aşa cum va mărturisi Andrei Codrescu mai târziu. După traducerea din 1989 a operei poetice aparținînd lui Lucian Blaga $^{3}$, Andrei Codrescu l-a recitit pe Blaga împreună cu profesorul, eseistul, criticul literar şi traducătorul Marcel Corniş Pop, stabilit în Statele Unite din 1983. După traducerea volumului La curțile dorului în 1989, cu titlul At the Court of Yearning: Poems by Lucian Blaga, translation. Columbus: Ohio State University Press, a urmat în 2019 traducerea volumului Lauda somnului în limba engleză, In Praise of Sleep: Selected Poems of Lucian Blaga (Commonwealth Books, Black Widow).

Andrei Codrescu se numără printre creatorii cu trei sau patru limbi materne (germana, idish, maghiara, româna) care şi-au clădit cariera în cea de a patra limbă, engleza. În timpul celor şase luni petrecute în Italia a mai scris versuri în limba română. Şi-a scris versurile pe cartea unei poetei italience care i-a desenat-o şi adăugat-o cu propriile-i versuri, din lipsă de hârtie, cartea a călătorit în America, s-a pierdut într-un bar, s-a descoperit după patruzeci de ani într-o bibliotecă şi s-a transformat în carte obiect, fiind tipărită într-un timp record în România. După stabilirea în 1966 în Statele Unite, Andrei Codrescu nu a mai scris în română, dar în ultimii ani a început să îşi aştearnă din nou ideile în română. În poemul său A Geography of Poets scria:

is all wrong, ed

what poets now live

where they say they do

where they started out

where they want to

half the midwesterners

did time in new york

the other half in california

3 Blaga, Poezii. Poems (1983); Blaga, At the Court of Yearning. Poems by Lucian Blaga (1989); Blaga, Poezii. Poems (1995); Blaga, Zalmoxis (2001); Blaga, Complete Poetical Works of Lucian Blaga, 1895-1961 (2001); Blaga, Strofe de-a lungul anilor / Stanzas Along the Years (2003). 
only new yorkers write as if they are from new york

and mostly they are not

the ones in california were wounded elsewhere when they feel better or can't afford the rent they'll go back where they came from

this is america you get hurt where you are born you make poetry out of it as far from home as you can get you die somewhere in between

the only geography of poets is greyhound general motors rules them all ubi patria ibi bene or ibi bene ubi patria bread out of nostalgia not a lot of it either some of us came from very far maps don't help much.

Andrei Codrescu, It Was Today: new poems (2003)

Andrei Codrescu a mărturisit că prima sa limbă a fost germana, dialectul schwab vorbit la Sibiu pe care îl vorbea cu mama sa, în timp ce cu bunica vorbea maghiara, cu prietenii vorbea româna. Învățată la şcoală, româna l-a înnobilat când a debutat sub numele de Andrei Steiu în România literară şi în Luceafărul. Tot ea i-a oferit distincția rafinată, alchimică poate şi după mai bine de un sfert de veac de exil, când în 2006 a scris o carte împreună cu teologul Robert Lazu publicată la Timişoara (Codrescu 2006). Colaborarea cu Ruxandra Cesereanu i-a adus noi satisfacții editoriale4 pentru că limba română a rămas în formația intelectuală de bază a autorului, structurându-i şi modelându-i capacitatea de exprimare. Edițiile lirice bilingve sau retrospective în limba română şi engleză 5 au fost publicate de către editurile din România care l-au făcut

4 Codrescu \& Cesereanu Submarinul iertat (2007), translated by Codrescu as The Forgiven Submarine (2009). Submarinul Iertat by Ruxandra Cesereanu \& Andrei Codrescu Anniversary Edition with Epistolary, Bucharest: Editura Charmides, 2017. Ediția a doua adăugită cu Întâiul final al cărții, urmat de Epistolar şi de poemul Ospățul alchimic. Cu o prefață de Mircea Cărtărescu şi Şase ilustrații de Radu Chio.

5 Codrescu, The Art of Forgetting: new poems (2016); Codrescu, Femeia neagră a unui 
cunoscut publicului din noul mileniu. Poezia, arta ultimelor cuvinte este un spectacol unic de sensibilitate şi efervescență luminoasă, ce surprinde miracolul cotidian cu acribie, melancolie meditativă şi autoironie încântând cititorul, iar opiniile despre poezie şi minunea exprimării plastice prin vibrația cuvintelor sunt de asemenea subiect de poezie (Codrescu 1996 şi Codrescu 1997). Miracolul călătoriei lingvistice prin intermediul traducerii şi al repovestirii este surprins de autor în versuri cu o profunzime filosofică şi cu revelații despre geografia lingvistică pe care trebuie să o cunoască şi să o parcurgă călătorul inițiat care este poetul traducător. Spre deosebire de generațiile anterioare de poeți traducători din limba română în limbile de circulație şi civilizație ale momentului, spre deosebire de Vasile Alecsandri care şi-a scris poeziile doar în română, realizând traduceri în limba franceză şi o gramatică a limbii române în limba franceză, semnată V. Mircesco prefațată de A. Ubicini (Mircesco 1863), Andrei Codrescu este poet în română şi în engleză inclus deopotrivă în patrimoniul cultural al ambelor literaturi, care îşi publică volumele în variantă bilingvă şi care are filosofice dileme despre miracolul înțelegerii prin intermediul poeziei:

\footnotetext{
Oare aici începe acolo sau aici?

Este arabă sau sanscrită şi oare mai este încă un calendar de perete gregorian sau ebraic ce nu e despre timp, un calendar de poveşti.

Locul unde ești ce erai odată este acolo

Pierdut într-una din acele poveşti absurde

În care erai cumva acasă şi altundeva deopotrivă.

Şi unde sunt acum cei care te ştiau atunci?

Când călătoreşti între limbi

Ce costum porți, ce valiză cari?
}

\section{Andrei Codrescu, The Art of Forgetting: new poems (2016).}

În concepția lui Andrei Codrescu, nu geografia sau actul de naştere îl fac pe un scriitor să aparțină unei literaturi, ci limba, ca instrument al cunoaşterii şi al esteticii, al exprimării lingvistice ca întrupare fizică a emoției. $\mathrm{Cu}$ alte cuvinte, multilingvismul exprimat literar este un avantaj indiscutabil, comparativ cu alte generații de scriitori. Fără îndoială că şi experința plecării ca exilant în America a jucat un rol important în acest caz. Tema centrală a creației sale este cea a limbajului, care îl transformă pe cel care îl foloseşte într-un introvertit, un creator a cărui temă esențială este legată de această meditație pe tema limbii şi a limbajului creației. Limbajul totuşi rămâne străin omului deoarece fiecare cuvânt este

culcuş de hoți (2007); Codrescu, Instrumentul negru. Poezii, 1965-1968 (2005); Codrescu, Poezii alese/Selected Poetry (2000). 
încărcat până la refuz de sensuri opuse. Într-una dintre conferințe, Andrei Codrescu spunea că limbajul pare să fi venit din cosmos asemeni unui virus, care a modificat capacitatea de exprimare a dorințelor omeneşti. Capacitatea cuvântului de a exprima formele opuse în interiorul aceleiaşi forme este evidentă în limbile vechi, în care creatul şi increatul au aceeaşi rădăcină semantică. Poet tragic cu un umor care învăluie exprimarea directă, brutală în vălul care face suportabilă exprimarea adevărurilor fruste, Andrei Codrescu este un spirit optimist, un poet confesiv, care şi-a păstrat uimirea pentru miracolul literaturii fără să se afilieze niciunei şcoli poetice din America.

Iubitor al exprimării prin radio şi televiziune, înțelegând funcția de creație a imaginii față de cea a cuvântului scris, câştigător al unui valoros premiu Peabody Award în 1995 pentru filmul său Road Scholar, Andrei Codrescu este un spirit inovator în tot ceea ce întreprinde, un cercetător al perioadei postcomuniste, considerate de scriitor o perioadă de convalescență mai lungă decât boala însăşi, o perioadă care a preluat tot ceea ce a fost mai rău din activism şi din comunism.

Conştient că vizibilitatea creației joacă un rol aparte alături de receptarea operei de către un public divers, premiat cu numeroase şi diverse distincții literare (MacCurdy Distinguished Professor of English, Louisiana State University; Peabody Award for Road Scholar; Ovid Prize; National Endowment for the Arts Fellowships for poetry; Big Table Poetry Award; Lowell Thomas Gold Award for Excellence in Travel Journalism; Towson State University Literature Prize; General Electric Foundation Poetry Prize; ACLU Freedom of Speech Award; Mayor's Arts Award, New Orleans; Literature Prize Fundația Culturală Română), Andrei Codrescu rămâne fidel călătoriei sale, urmând firul râului destinului său care l-a adus în lumină, acolo unde puterea de creație i-a fost apreciată, stimulată şi amplificată.

Plecat din lumea cu o mitologie specială a Transilvaniei patriarhale, în care Cuvintele fac lumea, Cuvintele au urmări şi nu trebuie rostite oricum, căci poetul este puțin asemănător lui Dumnezeu, Andrei Codrescu a reuşit să îşi dezvăluie potențialul creator şi să şi-l pună în lumină pentru a fi model şi altar al Cuvântului deopotrivă:

Din cărți am făcut cărămizi.

Am ridicat turnuri cu ele şi case.

Un călător poate citi titlurile pe spinare,

cu binoclul de la mari distanțe.

Care din ele sunt cele pe care le-am scris?

Încuiate pe veci într-o căsuță la marginea lumii.

În ea trăiesc copiii imaginilor.

Odată îi cunoaştem, odată îi cunoşteam.

Se trăgeau din cerneala cu care le construisem viitorul 
unde locuiesc şi astăzi fără nelinişte.

Alfabetul îi visează.

În vise literele-i recunosc.

Andrei Codrescu, Metroul F. Doi ani pe româneşte (2019).

\section{Bibliografie}

Blaga, Lucian. (1983). Poezii. Poems, bilingual edition, edited by Michael Taub, 16 poems translated by Ştefan Avădanei, Andrei Bantaş, Donald Eulert, Roy MacGregorHastie, Alfred Margul-Sperber, Michael Taub et al. Chapell Hill: University of North Carolina Press.

Blaga, Lucian. (1989). At the Court of Yearning. Poems by Lucian Blaga, translated by Andrei Codrescu. Columbus: Ohio State University Press.

Blaga, Lucian. (1995). Poezii. Poems, 118 poems translated by Mihail Bogdan, preface by Ştefan Aug. Doinaş. Sibiu: Sibiu University Press.

Blaga, Lucian. (2001a). Zalmoxis, translated by Doris Platnus-Runey, introduction by Keith Hitchins. Iaşi: Center for Romanian Studies; Deddington: Drake.

Blaga, Lucian. (2001b). Complete Poetical Works of Lucian Blaga, 1895-1961, translated by Brenda Walker with Stelian Apostolescu, foreword by Mircea Borcilă, introduction by Keith Hitchins. Iaşi: Center for Romanian Studies, BAR II 805754 .

Blaga, Lucian. (2003). Strofe de-a lungul anilor / Stanzas Along the Years, bilingual edition, translated by Dumitru Ciocoi-Pop, foreword by Ştefan Augustin Doinaş, afterword by Anthony O' Keeffe. Bucharest: The Romanian Cultural Foundation Publishing House.

Cesareanu, Ruxandra and Andrei Codrescu. (2009). The Forgiven Submarine, translated by Andrei Codrescu. Boston: Black Widow Press.

Codrescu, Andrei şi Ruxandra Cesereanu. (2007). Submarinul iertat, with Ruxandra Cesereanu, Timişoara, Romania: Editura Brumar.

Codrescu, Andrei şi Ruxandra Cesereanu. (2017). Submarinul Iertat by Ruxandra Cesereanu \& Andrei Codrescu Anniversary Edition with Epistolary. Bucureşti: Editura Charmides, Ediția a doua adăugită cu Întâiul final al cărții, urmat de Epistolar şi de poemul Ospățul alchimic. Cu o prefață de Mircea Cărtărescu şi Şase ilustrații de Radu Chio.

Codrescu, Andrei. (1970). Licence to Carry a Gun. Chicago: Big Table Pub Co.

Codrescu, Andrei. (1972). The, Here, What, Where. San Francisco: Isthmus Press.

Codrescu, Andrei. (1973a). \& Grammar \& Money. Berkeley: Arif Press.

Codrescu, Andrei. (1973b). A Serious Morning. Santa Barbara, Calif: Capra Press.

Codrescu, Andrei. (1973). The History of the Growth of Heaven. New York: Braziller.

Codrescu, Andrei. (1981). Diapers on the Snow. Ann Arbor, Mich: Crowfoot.

Codrescu, Andrei. (1983). In America's Shoes. San Francisco: City Light Books.

Codrescu, Andrei. (1986a). A Craving for Swan. Columbus: Ohio State University Press.

Codrescu, Andrei. (1986b). Comrade Past \& Mister President: New Poems \& a Journal. Minneapolis, Mn: Coffee House Press.

Codrescu, Andrei. (1987). Monsieur Teste in America \& Other Instances of Realism: Short Stories. Minneapolis: Coffee House Press.

Codrescu, Andrei. (1991). Belligerance: new poems. Minneapolis, Minn: Coffee House Press. 
Codrescu, Andrei. (1991). The Hole in the Flag: a Romanian Exile's Story of Return and Revolution. New York: W. Morrow.

Codrescu, Andrei. (1993a). Road Scholar: Coast to Coast Late in the Century. New York: Hyperion.

Codrescu, Andrei. (1993b). The Muse is Always Half Dressed in New Orleans and Other Essays. New York: St Martin's Press.

Codrescu, Andrei. (1994). Zombification: Stories from National Public Radio. New York: St Martin's Press.

Codrescu, Andrei. (1995). Over America. San Francisco: Weldon Owen in association with KCTS, Seattle.

Codrescu, Andrei. (1996a). Alien Candor: Selected Poems, 1970-1995. Santa Rosa, Calif: Black Sparrow press.

Codrescu, Andrei. (1996b). The Blood Countess. London: Quartet Books.

Codrescu, Andrei. (1996c). The Dog with the Chip in His Neck: Essays from NPR and Elsewhere. New York: St Martin's Press.

Codrescu, Andrei. (1997). Alien Candor Candoare străină poeme alese. Bucureşti: Editura Fundației Culturale Române.

Codrescu, Andrei. (1999a). A Bar in Brooklyn: Novellas and Stories. 1979-1978. Santa Rosa, Calif: Black Sparrow Press.

Codrescu, Andrei. (1999b). Ay, Cuba! A Socio-erotic Journey. New York: St Martin's Press.

Codrescu, Andrei. (1999). Messiah: a Novel. New York: Simon \& Schuster,

Codrescu, Andrei. (2000a). Poezii alese/Selected Poetry, bi-lingual edition, English and Romanian. Bucharest: Editura Paralela 45.

Codrescu, Andrei. (200ob). Selected Poetry/ Poezii alese. Piteşti: Paralela 45 Publishing House.

Codrescu, Andrei. (2001). An Involuntary Genius in America's Shoes: and What Happened Afterwards. Santa Rosa, Calif: Black Sparrow.

Codrescu, Andrei. (2001). Herman, Lloyd E., Thomas Mann: Metal Artist. foreword by Michael W. Monroe, Madison, Wis: Guild Publishers.

Codrescu, Andrei. (2003). It Was Today: new poems. Minneapolis, Minn: Coffee House Press.

Codrescu, Andrei. (2005). Instrumentul negru. Poezii, 1965-1968. Craiova: Scrisul Românesc.

Codrescu, Andrei. (2006). Miracol şi catastrofă: Dialogues in Cyberspace with Robert Lazu. Timişoara: Hartman.

Codrescu, Andrei. (2006). New Orleans, Mon Amour: Twenty Years of Writings from the City. Chapel Hill, NC: Algonquin Books of Chapel Hill.

Codrescu, Andrei. (2007). Femeia neagră a unui culcuş de hoți, Bucharest: Editura Vinea.

Codrescu, Andrei. (2009). The Posthuman Dada Guide: Tzara \& Lenin Play Chess. Princeton, NJ, Woodstock: Princeton University Press.

Codrescu, Andrei. (2010). The Poetry Lesson, Princeton, NJ, and Woodstock: Princeton University Press.

Codrescu, Andrei. (2011). Whatever Gets You through the Night: A Story of Sheherezade and the Arabian Entertainments. Princeton, Oxford: Princeton University Press.

Codrescu, Andrei. (2016). The Art of Forgetting: New Poems, translated into Romanian by Alexandru Oprescu, Zalău: Editura Caiete Silvane.

Codrescu, Andrei. (2019). Metroul F. Doi ani pe româneşte. Craiova: Scrisul Românesc. 
Gheo, Radu Pavel. (2017). Străin în țară străină: Literatura română şi graniţa identitară în proza Hertei Müller şi a lui Andrei Codrescu. Timişoara: Editura Universității de Vest.

Mircesco, V. (1863). Grammaire de la Langue Roumaine par V. Mircesco précédée d'un aperçu historique sur la langue roumaine par A. Ubicini. Paris: Maisonneuve et Cie Librairies Éditeurs 15 Quai Voltaire 15.

Rosenfeld Alvin H. (2008). The Writer Uprooted: Contemporary Jewish Exile Literature (Jew Literature and Culture). Bloomington: Indiana University Press.

Strugaru, Oana. (2013). Exilul ca mod de existență. Andrei Codrescu în spațiul textual al dezrădăcinări. Bucureşti: Editura Muzeul Literaturii Române.

Vănoagă, Cristina-Matilda. (2019). Proza lui Andrei Codrescu. Spații între realitate şi imaginar. Bucureşti: Tracus Arte. 